\title{
ANALISIS, IDENTIFIKASI PRECURSOR DAN HASIL DEGRADASI SENYAWA SENJATA KIMIA MENGGUNAKAN TEKNIK GAS CHROMATOGRAPHY MASS SPECTROMETRY-ELECTRON IONISASI (GCMS-EI)
}

\author{
ANALYSIS, PRECURSOR IDENTIFICATION AND DEGRADATION CHEMICAL \\ COMPOUNDS RELATED TO CHEMICAL WEAPONS USING GAS \\ CHROMATOGRAPHY MASS SPECTROMETRY-ELECTRON \\ IONISASI (GCMS-EI)
}

\author{
Evita Boes \\ Pusat Penelitian Kimia - Lembaga Ilmu Pengtahuan Indonesia \\ Jl. Sangkuriang 21/54 D Bandung 40135 \\ Email : evitaboes@yahoo.com
}

Diterima : 19 Januari 2014, Revisi : 29 Januari 2014, Disetujui : 6 Februari 2014

\begin{abstract}
ABSTRAK
Telah dilakukan analisis, identifikasi precursor dan hasil degradasi senyawa senjata kimia diethyl methylphosphonat (DEMP), methyl phosphonic acid (MPA) dalam sampel air dan dimethyl methyl phosphonat (DMMP), ethyl phosphonic acid (EPA) dalam sampel tanah. Contoh yang dianalisa merupakan contoh senyawa tributilphosphat (TBP) $40 \mathrm{ug} / \mathrm{mL}$ dan poliethilene glycol $56,24 \mathrm{ug} / \mathrm{mL}$ ditambahkan sebagai background dan sampel tanah kering yang berpasir. Identifikasi dilakukan dengan metode kromatografi gas spektrometri massa - elektron ionisani (GCMS-EI). Ekstraksi fasa organik pada $\mathrm{pH}$ netral, sililasi dari fasa air yang diuapkan, di mana triethylamine/methanolsililasi dan kation exchange-sililasi digunakan untuk ekstraksi senyawa - senyawa precursor dan hasil degradasi sebelum diinjeksikan ke GCMS. Dari hasil analisis diperoleh waktu retensi 8,9 dan 10,97 menit masing - masing untuk diethyl methylphosphonat dan bis(trimethylsilyl) methylphosphonate dalam sampel air sedangkan dalam sampel tanah 6,62 dan 12,06 menit untuk dimethyl methylphosphonat dan bis(trimethylsilyl) ethylphosphonate. Total Ion Chromatography (TIC) yang dihasilkan dari GCMS dievaluasi dengan menggunakan Library Data Base NIST (National Institute of Standards and Technology), dan AMDIS (Automated Mass Spectral Deconvolution and Identification System). Spektrum yang dihasilkan memberikan nilai base peak pada $\mathrm{m} / \mathrm{z}=97$ untuk diethyl methylphosphonate, $\mathrm{m} / \mathrm{z}=225$ untuk bis(trimethylsilyl) methylphosphonate, $\mathrm{m} / \mathrm{z}=94$ untukdimethyl methylphosphonate dan $\mathrm{m} / \mathrm{z}=239$ untuk bis(trimethylsilyl) ethylphosphonate sedangkan retention index (RI) yang dihitung digunakan untuk mengonfirmasi masing-masing senyawa precursor
\end{abstract}

Kata kunci : precursor, degradsi senyawa senjata kimia, base peak, waktu retensi, Total Ion Kromatografi.

\section{ABSTRACT}

Analysis, precursorand identification have been done and degradation compoundsof chemical weapon diethyl methylphosphonat, methyl phosphonic acid in water matrices, dimethyl methylphosphonat and ethyl phosphonic acidin soil samples. Water used for extracting those compounds was an example of simulation that contain tributilphosphat (TBP) $40 \mathrm{ug} / \mathrm{mL}$ and poliethylene glycol $56,24 \mathrm{ug} / \mathrm{mL}$ which added as a background and dry sandy soil samples. Identification was done by using Gas Chromatographic Mass Spectrometry - Electron Ionization (GCMS-EI) method. Neutral organic extraction, evaporated water - silylation, triethylamine/methanol-silylation and cation exchanged-silylation were performed to extract the precursor's compounds from the samples, before being analyzed by gas chromatography mass spectrometry. The result of the analysis by Gas Chromatographic Mass Spectrometry method showed that the retention time (in min) was 8,9 and 10,97 for diethyl methylphosphonat and bis(trimethylsilyl) methylphosphonate in the water sample, while the retention time in soil sample was 6,62 and 12,06 for dimethyl methylphosphonat and bis(trimethylsilyl) ethylphosphonate. The result of Total Ion Chromatography (TIC) from GCMS was evaluated using NIST (National Institute of Standards and Technology) database library and AMDIS (Automated Mass Spectral Deconvolution and Identification System). The spectrum's result gave the value of base peak, which are $\mathrm{m} / \mathrm{z}=97$ for diethyl methylphosphonat, $\mathrm{m} / \mathrm{z}=225 \mathrm{for}$ bis(trimethylsilyl) methylphosphonate, $\mathrm{m} / \mathrm{z}=$ 94 for dimethyl methylphosphonat and $\mathrm{m} / \mathrm{z}=239$ for bis(trimethylsilyl) ethylphosphonate. On the other hand, the retention indice (RI) calculation was used to get the confirmation of each compounds of precursors.

Keywords: precursor, degradation of chemical weapon, base peak, retention time, totalion chromatography.. 


\section{PENDAHULUAN}

Senyawa senjata kimia dilarang untuk dikembangkan, diproduksi, disimpan dan digunakan kecuali untuk tujuan yang tidak dilarang oleh konvensi senjata kimia seperti industri, pertanian, farmasi dan penelitian . Senyawa senjata kimia bersifat sangat toksik dan memberikan efek yang cepat pada tubuh. Senyawa senjata kimia baik yang berbentuk gas, aerosol atau liquid masuk ke dalam tubuh melalui sistem pernafasan, kulit atau dapat juga masuk melalui makanan dan minuman yang sudah terkontaminasi. Pada umumnya senyawa beracun cepat memberikan efek pada tubuh ketika zat tersebut masuk melalui sistem respirasi, itu disebabkan karena zat tersebut dapat dengan mudah untuk berdifusi dalam sirkulasi darah dan mencapai organ penting tubuh. Senyawa beracun akan memberikan efek lama ketika senyawa tersebutmasukmelalui kulit. ${ }^{(1,2)}$

Jumlah dan jenis senyawa senjata kimia sangat beragam dan dituangkan dalam Schedule Chemical yang dibagi dalam tiga kategori yaitu Schedule 1 merupakan daftar toxic chemical dan precursor yang memiliki resiko tinggi, Schedule 2 merupakan daftar toxic chemical dan precursor yang memiliki resiko cukup tinggi dan Schedule 3 merupakan daftar toxic chemical dan precursor yang mungkin digunakan untuk kegiatan-kegiatan yang dilarang oleh konvensi. Senyawa senjata kimia terutama senyawa organik yang jenisnya bervariasi dengan sifat-sifat fisika dan kimia yang sangat berbeda ada yang bersifat senyawa kimia netral, asam, basa, mudah menguap, sukar menguap dan yang berikatan dengan heteroatom phosphor, sulfur, arsen, fluorin dan klorin. Bahan yang digunakan untuk membuat senyawa senyawa kimia berbahaya dikatakan sebagai precursor dan precursor juga bisa berasal dari degradasi senyawa senjata kimia berbahaya. ${ }^{(2)}$

Salah satu metoda yang dikembangkan untuk identifikasi dan analisis senyawa senjata kimia dan precursornya adalah metode kromatografi, baik kromatografi gas spektrofotometri massa (GCMS) maupun kromatografi cair spektrofotometri massa (LCMS). Metode ini sangat cocok untuk digunakan dalam mengidentifikasi senyawa senjata kimia dan precursornya karena mempunyai kemampuan analisis dengan akurasi dan sensitifitas yang tinggi. ${ }^{(3,4,5)}$

Kromatografi gas spektrofotometri massa (GCMS) dapat digunakan untuk identifikasi dan analisis senyawa senjata kimia dan precursor yang mudah menguap ataupun yang sukar menguap yang diderivatisasi terlebih dahulu sebelum dianalisis dengan GCMS. Teknik Electron Ionization (EI) dan Chemical Ionization $(\mathrm{CI})$ dapat digunakan untuk identifikasi senyawa senjata kimia yang ada dalam sampel. Analisa dengan GCMS dengan teknik ionisasi (EI) sering menghasilkan fragmentasi yang luas yang memberikan informasi penting untuk struktur senyawa kimia sedangkan teknik ionisasi CI dengan metana, ammonia atau isobutan sebagai reagen gas hanya memberikan informasi berat molekul. ${ }^{(6,7)}$

Preparasi sampel memegang peranan sangat penting dalam analisis senyawa senjata kimia. Metode preparasi sampel yang tidak tepat dan cocok dengan sifat kimia dan fisika dari suatu sampel atau dengan metode pengukuran yang dipilih akan menyebabkan kesalahan dalam analisis. Pada umumnya preparasi sampel untuk analisis senyawa senjata kimia dilakukan dengan ekstraksi, evaporasi, derivatisasi dan pemekatan. Metode ekstraksi yang paling effisien adalah sonikasi namun hal yang harus diperhatikan yaitu fraksi harus secepatnya dipisahkan setelah proses sonikasi, supaya tidak ada komponen yang teradsorpsi kembali (misalnya dalam ekstraksi sampel tanah).

Menurut Robin M.Black dan Bob Muir ${ }^{(8)}$, sifat senyawa senjata kimia yang tidak mudah menguap harus diubah kedalam bentuk derivatnya agar dapat dianalisa dengan menggunakan metode kromatografi gas atau kromatografi gas spektrometri masa. Derivat trimetilsilil (TMS) dari alkil fosfonat dan aminoalkilfosfonat yang mengandung gugus amino primer ditemukan sangat tepat. Dengan adanya metode pembentukan trimetilsilil ester, maka senyawa ini mudah larut dan dikarakterisasi. Untuk menyempurnakan reaksi, diperlukan juga pemanasan pada temperature antara $60-70^{\circ} \mathrm{C}$.

Dalam sililasi terutama dalam sampel air atau tanah, salah satu yang menjadi masalah adalah keberadaan ion-ion dalam sampel, ion-ion tersebut akan menghambat proses sililasi dari senyawa senjata kimia seperti alkilphosphonic acid dan dialkilalkilphosphonic acid. Untuk menghilangkan ion-ion, sampel terlebih dahulu dilalui kedalam catridge kation exchange (SCX), dinetralkan sebelum disililasi dengan BSTFA. ${ }^{(6,9)}$

Tujuan penelitian ini adalah identifikasi dan analisis senyawa senjata kimia dan precursor yang terdapat dalam sampel air dan tanah menggunakan GCMS-EI dengan teknik preparasi ekstraksi dan 
derivatisasi ( untuk senyawa-senyawa yang bersifat non polar dan polar).

Penentuan waktu retensi dapat digunakan sebagai salah satu kriteria dalam mengidentifikasi suatu senyawa. Kriteria lain yang lebih dapat dipercaya ialah pengukuran indeks retensi (Retention Indice) yaitu parameter yang tidak memiliki dimensi, yang mengubah waktu retensi suatu senyawa menjadi nilai baru yang kurang tergantung pada perubahan kecil yang terjadi pada kondisi kromatografi dibandingkan dengan waktu retensi. Nilai RI yang dihitung dari sampel dibandingkan dengan RI yang ada di Library dengan perbedaan yang tidak boleh lebih dari 20 unit. $^{(10,11)}$

\section{BAHAN DAN METODA}

\section{Bahan}

Asetonitril dan diklorometane dengan kualitas kromatografi (E.Merck), natrium sulfat anhidrous, triethyl amin (TEA), metanol, asam klorida, natrium hidroksida dan pereaksi derivatisasi Bis(Trimethylsilil)-trifluoroasetamida (BSTFA) Aldrich, gas helium (UHP), nitrogen, SCX Cartridge Supelco $100 \mathrm{mg}$ dan vial volume 1,3 dan $5 \mathrm{~mL}$.

\section{Peralatan}

Gas Chromatography Mass Spectrometer (GC/MS) Shimadzu QP 2010 menggunakan kolom DB5MS $(30 \mathrm{~m} \times 0,25 \mathrm{~mm} \times 0,25 \mu \mathrm{m})$ dengan mode Electron Impact Ionization (EI), Library NIST, AMDIS dan OCAD (OPCW Central Analytical Database (OCAD) Library)alat evaporasi yang dilengkapi dengan aliran gas nitrogen.

\section{Metoda}

Kondisi Gas Chromatography Mass SpectrometryElectron Ionization (GC-EI-MS)

Gas Chromatography Mass Spectrometry Shimadzu QP 2010, kolom DB-5MS (30 m x 0,25 mm x $0,25 \mu \mathrm{m})$. Ionization polarity : positif, energy elektron $70 \mathrm{eV}$, scan range $40-400 \mathrm{~m} / \mathrm{z}$ (model EI). Menggukan gas pembawa helium, diatur pada kecepatan alir 0,9 $\mathrm{mL} /$ menit. Splitless injection pada splitlesstime 0,7 menit, temperature injector $250^{\circ} \mathrm{C}$. Temperatur kolom terprogram: temperature awal $40^{\circ} \mathrm{C}$ ( 2 menit), rate $10^{\circ} \mathrm{C} /$ menit, temperatur akhir $280^{\circ} \mathrm{C}(4$ menit $)$.

\section{Verifikasi Gas Chromatography Mass Spectrometri -Electron Ionization (GC-EI-MS)}

Menginjeksikan $1 \mathrm{uL}$ larutan quality kontrol (Testmixture) yang terdiri dari , 5 chloro-2-methyl anilin, 2-6 dimethylphenol, dibenzothiophene, tributhylphosphat dan hexachlorobenzene dan seri hidrokarbon $\left(\mathrm{C}_{8}-\mathrm{C}_{24}\right)$ untuk menghitung Retention Index (RI) senyawa precursor dalam contoh. Untuk analisa sampel, $1 \mathrm{uL}$ dari setiap tahap preparasi di injek ke GCMS.

\section{Persiapan contoh dalam matrik air}

Contoh air yang digunakan adalah air kran yang telah disaring dengan menggunakan membrane filter millipore. Terhadap contoh air ditambahkan standar campuran yang mengandung 4 senyawa kimia sebagai berikut :

- Senyawa diethyl methylphosphonat (DEMP) 11 $\mathrm{ug} / \mathrm{mL}$ dan methyl phosphonic acid (MPA) $38,7 \mathrm{ug} / \mathrm{mL}$

- Senyawa tributilphosphat (TBP) $40 \mathrm{ug} / \mathrm{mL}$ dan poliethilene glycol $56,24 \mathrm{ug} / \mathrm{mL}$ ditambahkan sebagai background.

- Blanko yang digunakan adalah air kran yang hanya mengandung dichloromethane.

- Terhadap contoh uji yang telah mengandung 4 senyawa kimia dan contoh uji blanko selanjutnya dipreparasi sebagai berikut:

Preparasi senyawa precursor yang bersifat non polar

- Sebanyak $5 \mathrm{~mL}$ masing-masing contoh uji dan blanko dinetralkan hingga $\mathrm{pH} 7$ menggunakan $0,1 \mathrm{~N} \mathrm{HCl}$ atau $0,1 \mathrm{NNH}_{4} \mathrm{OH}$.

- Contoh air diekstraksi dengan $2 \times 2,5 \mathrm{~mL}$ diklorometan selama 10 menit

- Pisahkan lapisan diklorometan dari air dan lapisan diklorometan ditambahkan $\mathrm{Na}_{2} \mathrm{SO}_{4}$ anhydrous, sedangkan lapisan air akan digunakan untuk identifikasi selanjutnya.

- Ambil 1mL lapisan diklorometan pindahkan ke vial dan diuapkan sampai volume $0,1 \mathrm{~mL}$ dengan mengalirkan nitrogen.

- Hasil preparasi ini injek ke GCMS dengan kode Water DCM (sampel air ekstrak dengan diklorometan) dan Blanko DCM (blanko air ekstrak dengan diklorometan) 
- Evaluasi setiap puncak pada kromatogramm ion total (TIC) dilakukan dengan menggunakan NIST Library dan AMDIS.

\section{Preparasi senyawa precursor yang bersifat polar}

- Fasa air setelah ekstraksi dengan diklorometan masing-masing contoh uji dan blanko dimasukkan dalam tabung evaporasi dan dievaporasi pada temperatur $60^{\circ} \mathrm{C}$ dengan mengalirkan nitrogen sampai kering.

- Hasil evaporasi larutkan dengan 0,5 mL asetonitril dan sililasi dengan menambahkan 0,5 mL BSTFA, panaskan pada suhu $60^{\circ} \mathrm{C}$ selama 30 menit.

- Hasil sililasi diinjek ke GCMS dengan kode Water BSTFA (sampel air yang disililasi dengan BSTFA) dan Blanko BSTFA (blanko air yang disililasi dengan BSTFA).

- Evaluasi setiap puncak pada kromatogramm ion total dilakukan dengan menggunakan NIST/ Library dan AMDIS.

\section{Persiapan contoh dalam matriks tanah ${ }^{(12)}$}

Tanah yang digunakan tanah berpasir yang kering. Terhadap contoh tanah 4 gr tambahkan ethyl phosphonic acid (EPA) 10,22 ug/g dan dimethyl methyl phosphonat (DMMP) 10,8 ug/g. Contoh tanah yang telah ditambahkan standar ini didiamkan pada suhu ruang selama 1 jam sebelum dipreparasi. Terhadap contoh uji dan blanko, selanjutnya dilakukan preparasi sebagai berikut:

\section{Preparasi senyawa precursor yang bersifat non polar}

- Contoh tanah $\pm 5 \mathrm{~g}$ diekstraksi dengan $5 \mathrm{~mL}$ diklorometan secara manual dengan cara digoyanggoyangkan selama 5 menit.

- Setelah di ekstraksi kemudian di sentrifugasi selama 5 menit pada $3750 \mathrm{rpm}$. Pisahkan lapisan diklorometan dari tanah dan saring.

- Ulangi ekstraksi dengan $5 \mathrm{~mL}$ diklorometan, gabungkan hasil ekstraksi diklorometan

- Hasil ekstraksi diklorometan dievaporasi hingga volume $1 \mathrm{~mL}$ dengan mengalirkan gas nitrogen.

- Hasil evaporasi diinjeksikan ke GCMS dengan kode contoh Soil DCM (tanah yang diekstraksi dengan diklorometan dan Blanko DCM (blanko tanah yang diekstraksi dengan diklorometan).

- Evaluasi setiap puncak pada kromatogram ion total (TIC) dilakukan dengan menggunakan NIST Library dan $A M D I S$.
Preparasi senyawa precursor yang bersifat lebih polar

- Residu contoh tanah setelah diekstraksi dengan diklorometan (butir 2 diatas) diletakkan pada lemari asam kira-kira 1 jam sampai tanahnya kering.

- Contoh tanah yang kering ini diekstraksi dengan 2 x 5 mL aquades, secara manual dengan cara digoyanggoyangkan selama 5 menit

- Ekstrak dengan aquades ini dibagi dua :

- Bagian pertama ekstrak air ini diuapkan hingga kering dengan dimasukkan dalam tabung evaporasi dan dievaporasi pada temperature $60^{\circ} \mathrm{C}$ dengan mengalirkan nitrogen sampai kering.

- Tambahkan $2 \mathrm{~mL}$ triethylamin dalam methanol $1 \%$, evaporasi sampai kering Hasil evaporasi larutkan dengan $0,5 \mathrm{ml}$ asetonitril dan sililasi dengan menambahkan $0,5 \mathrm{~mL}$ BSTFA dan panaskan pada suhu $60^{\circ} \mathrm{C}$ selama 30 menit.

- Hasil sililasi diinjeksikan ke GCMS dengan kode Soil-TEA-BSTFA (sampel tanah yang diekstraksi dengan air dan disililasi dengan BSTFA) dan Blanko BSTFA (blanko tanah yang diekstraksi dengan air dan disililasi dengan BSTFA).

- Evaluasi setiap puncak pada kromatogramm ion total dilakukan dengan menggunakan NIST Library dan AMDIS.

Preparasi senyawa precursor yang bersifat lebih polar dengan SCX

- Cation Exchange Cartridge (SCX) dikondisikan dengan $1 \mathrm{~mL}$ methanol dan $1 \mathrm{~mL}$ air.

- Bagian kedua ekstrak air dilewatkan kedalan SCX dan eluat yang keluar dinetralkan terlebih dahulu sebelum dievaporasi sampai kering.

- Larutkan dengan $2 \mathrm{~mL}$ triethyl amine $1 \%$ dalam metanol, pindahkan ke vial dan evaporasi sampai kering dengan bantuan nitrogen.

- Residu di sililasi dengan menambahkan 0,5 mL acetonitril dan $0,5 \mathrm{~mL}$ BSTFA dan panaskan pada suhu $60^{\circ} \mathrm{C}$ selama 30 menit.

- Hasil sililasi diinjeksikan ke GCMS dengan kode Soil-TEA-SCX-BSTFA (sampel tanah yang diekstraksi dengan air, dilewatkan ke SCX dan disililasi dengan BSTFA) dan Blanko-BSTFA (blanko tanah yang diekstraksi dengan air, disililasi dengan BSTFA)

- Evaluasi setiap puncak pada kromatogramm ion total dilakukan dengan menggunakan NIST Library dan AMDIS. 


\section{HASIL DAN PEMBAHASAN}

\section{Kesesuaian Sistem Gas Chromatography Mass Spectrometry ${ }^{(2)}$}

Peralatan GCMS setiap kali akan digunakan dikalibrasi terlebih dahulu dengan injek $1 \mathrm{uL}$ Testmix untuk membuktikan bahwa peralatan telah memenuhi syarat untuk digunakan dan hasil kalibrasi pada Tabel 1 dapat dilihat waktu retensi (Rt) dari masing-masing standar dan Retention Indice (RI) yang dihasilkan setelah dibandingkan dengan data-data RI dari AMDIS, tidak memberikan nilai yang berbeda jauh dan nilai Match Factor (MF)/similaritas yang diberikan memenuhi syarat yaitu besar dari $900^{(2,10,11)}$

Tabel 1. Hasil Uji Kesesuaian Sistem GCMS

\begin{tabular}{lccc}
\hline \multicolumn{1}{c}{ Senyawa } & $\begin{array}{c}\text { Waktu retensi } \\
\text { (Rt)/menit }\end{array}$ & $\begin{array}{c}\text { Retention } \\
\text { Index (RI) }\end{array}$ & MF \\
\hline Octana & 5,06 & 800 & 98 \\
\hline Decana & 8,74 & 1000 & 98 \\
\hline 2,6 dimethyl phenol & 10,57 & 1113 & 99 \\
\hline Dodecana & 11,99 & 1200 & 97 \\
\hline 5-chloro 2-methyl aniline & 13,61 & 1314 & 97 \\
\hline Tetradecana & 14,83 & 1400 & 95 \\
\hline Hexadecana & 17,36 & 1600 & 98 \\
\hline TBP & 17,86 & 1643 & 98 \\
\hline Hexachlorobenzene & 18,71 & 1643 & 98 \\
\hline Dibenzothiophene & 19,42 & 1789 & 99 \\
\hline Octadecana & 19,63 & 1800 & 95 \\
\hline Eicosane & 21,69 & 2000 & 92 \\
\hline Docosane & 23,58 & 2200 & 93 \\
\hline Tetracosane & 25,31 & 2400 & 92 \\
\hline Hexacosane & 26,98 & 2600 & 98 \\
\hline Octacosane & 29,15 & 2800 & 94 \\
\hline
\end{tabular}

Tabel 2. Ratio intensitas ion isotop

\begin{tabular}{lcccc}
\hline No & Senyawa & $\mathrm{m} / \mathrm{z}$ & Ratio intensitas (\%) & Persyaratan (\%) \\
\hline 1 & 5-kloro2-methylaniline & $\begin{array}{c}143 / 141 \\
\left(\left.{ }^{37} \mathrm{Cl}\right|^{35} \mathrm{Cl}\right)\end{array}$ & 30,7 & $33 \pm 3 \%$ \\
\hline 2 & Benzotiophene & $186 / 184$ & 5,4 & $5,9 \pm 1 \%$ \\
& $\left({ }^{34} \mathrm{~S}^{32} \mathrm{~S}\right)$ & & \\
\hline
\end{tabular}

Analisis Diethyl Methylphosphonat (DEMP) dan Methyl Phosphonic Acid (MPA)

DEMP dan MPA adalah senyawa precursor yang ditambahkan ke matrik air (contoh air yang disimulasi). Ekstraksi dengan diklorometan pada $\mathrm{pH}$ netral dilakukan untuk mengekstrak DEMP. Dua gugus ethyl pada DEMP menyebabkan bersifat non polar. Total Ion Chromatography (TIC) dari hasil ekstraksi dengan diklorometan menunjukkan adanya intensitas puncak yang tinggi pada waktu retensi (Rt) 8,9 menit dan puncak ini tidak muncul pada larutan blanko yang juga ikut diinjek ke GCMS sebelum injek hasil ekstraksi diklorometan dari sampel, hal ini menunjukkan bahwa
DEMP hanya berasal dari sampel yang diekstraksi, sepertipada Gambar 1.
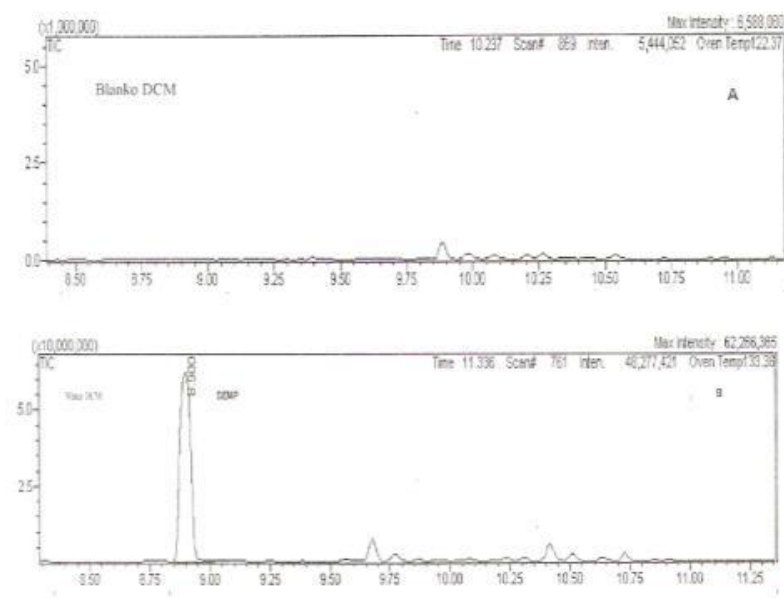

Gambar 1. Total Ion Chromatogram Diethyl Methylphosphonat

Spektrum massa dari puncak pada Rt 8,9 menit ini memberikan ion molekul pada $\mathrm{m} / \mathrm{z}=152$ dan base peak pada $\mathrm{m} / \mathrm{z}=97$ yang berasal dari fragmentasi $\left[\mathrm{CH}_{6} \mathrm{PO}_{3}\right]^{+}$. Fragmentasi ini terbentuk akibat hilangnya 2 gugus $-\mathrm{CH}-\mathrm{CH}_{3}$ dari DEMP $\left(\mathrm{C}_{5} \mathrm{H}_{13} \mathrm{O}_{3} \mathrm{P}\right)$. Spektrum pada $\mathrm{m} / \mathrm{z} 97$ yang merupakan base peak diikuti oleh adanya fragmentasi yang kehilangan molekul air pada $\mathrm{m} / \mathrm{z}=79$ yang karakteristik untuk grup dialkyl methylphosphonate. Secara keseluruhan fragmen yang lainnya terdiri dari $\mathrm{m} / \mathrm{z} 65,79,97,108,125,152^{(2 ., 3,4,5)}$ Spektrum ekstraksi diklorometan ini setelah dibandingkan dengan spektrum pada AMDIS Library memberikan hasil yang sama untuk senyawa Diethyl Methylphosphonat, sepertipada Gambar 2.

Methyl phosphonicacid(MPA) yang ditentukan dari fasa air setelah diekstraksi dengan diklorometan. Adanya gugus $\mathrm{OH}$ menyebabkan bersifat lebih polar dan tidak mudah menguap. Menurut Robin M.Black dan Bob Munir ${ }^{(8)}$ sifat senyawa yang tidak mudah menguap harus diubah ke bentuk derivatnya agar dapat dianalisa dengan menggunakan metode kromatografi gas/ atau kromatografi gas spektrometri massa. Derivatisasi dengan BSTFA akan membentuk derivate trimethylsilyl (TMS). Hasil derivatisasi MPA dengan BSTFA membentuk bis(trimethylsilyl) methylphosphonate yang merupakan senyawa yang lebih mudah menguap.

Total Ion Chromatography (TIC) yang dihasilkan menunjukkan adanya intensitas puncak yang tinggi pada waktu retensi (Rt) 10,97 menit, dan puncak ini 
tidak muncul pada larutan blanko yang juga ikut diinjek ke GCMS sebelum injek hasil derivatisasi BSTFA dengan MPA, hal ini menunjukkan bahwa MPA hanya berasal dari sampel fasa air yang diuapkan, seperti pada Gambar 3 .
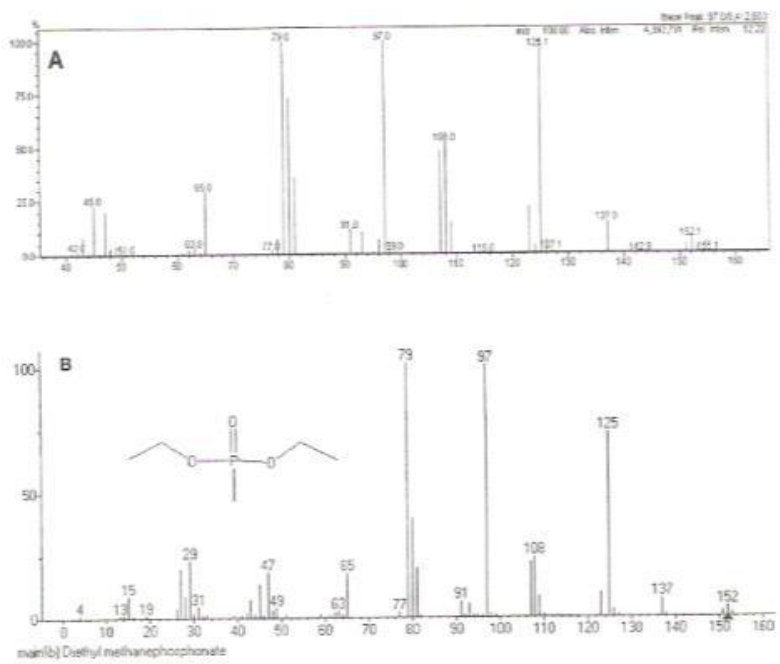

Gambar 2. Spektrum massa Diethyl Methylphosphonat
A. Spektrum masa Diethyl Methylphosphonat dari sampel air
B. Spektrum masa Diethyl Methylphosphonat (Library)
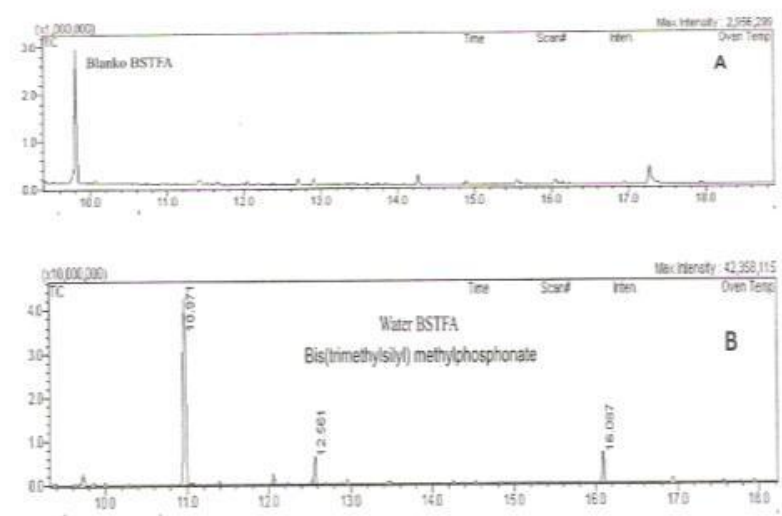

Gambar 3. Total Ion Chromatogram Bis(trimethylsilyl) methylphosphonate

Spektrum massa dari puncak pada Rt 10,97 menit ini menghasilkan ion molekul pada $\mathrm{m} / \mathrm{z}=240$ dan base peak pada $\mathrm{m} / \mathrm{z}=225$ yang berasal dari fragmentasi $\left[\mathrm{C}_{6} \mathrm{H}_{18} \mathrm{O}_{3} \mathrm{PSi}_{2}\right]^{+}$. Fragmentasi ini terbentuk akibat hilangnya gugus $-\mathrm{CH}_{3}$ dari bis(trimethylsilyl) methylphosphonate $\left(\mathrm{C}_{7} \mathrm{H}_{21} \mathrm{O}_{3} \mathrm{PSi}_{2}\right)$. Secara keseluruhan fragmentasi yang lainnya terdiri dari $\mathrm{m} / \mathrm{z} 73,133,147$, $225,240$. . $^{(2,3,4)}$
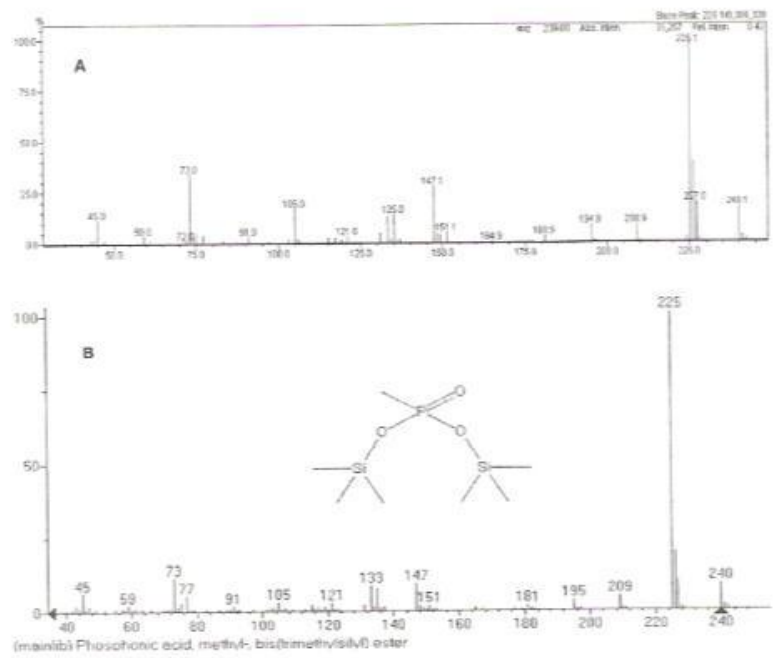

Gambar 4. Spektrum massa Bis (trimethylsilyl) methylphosphonate

A. Spektrum masa Bis(trimethylsilyl) methylphosphonate dari sampel air.

B. Spektrum masa Bis(trimethylsilyl) methylphosphonate (Library)

Analisis Dimethyl Methylphosphonat (DMMP) dan Ethyl Phosphonic Acid (EPA)

DMMP dan EPA adalah senyawa precursor yang ditambahkan ke matrik tanah (contoh yang disimulasi). DMMP dapat ditentukan dari ekstraksi dengan dikhlorometan karena dua gugus methyl pada DMMP menyebabkan bersifat non polar. Total Ion Chromatography (TIC) dari hasil ekstraksi tanah dengan dikhlorometan menunjukkan adanya intensitas puncak yang tinggi pada waktu retensi (Rt) 6,6 menit dan puncak ini tidak muncul pada larutan blanko yang juga ikut diinjek ke GCMS sebelum injek hasil ekstraksi dikhlorometan dari sampel tanah, hal ini menunjukkan bahwa DMMP hanya berasal dari sampel tanah yang diekstraksi, seperti pada Gambar 5.
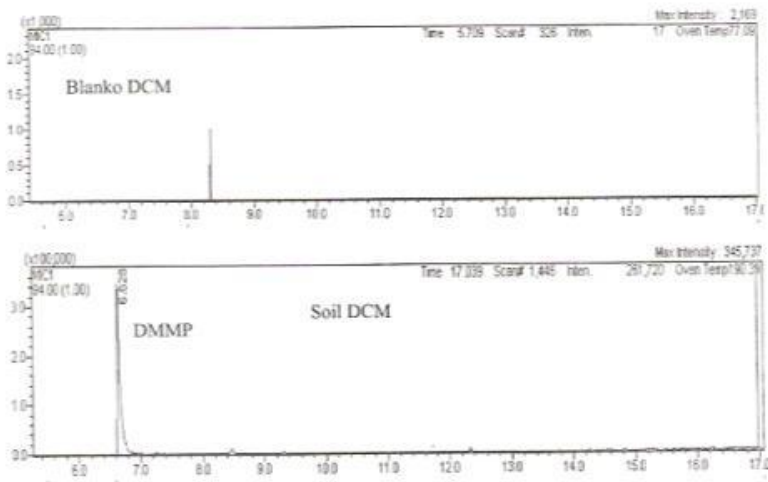

Gambar 5. Total Ion Chromatogram Dimethyl Methylphosphonat 
Spektrum massa dari puncak pada Rt 6,6 menit ini menghasilkan ion molekul pada $\mathrm{m} / \mathrm{z}=124$ dan base peak pada $\mathrm{m} / \mathrm{z}=94$ yang berasal dari fragmentasi $\left[\mathrm{CH}_{3} \mathrm{PO}_{3}\right]^{+}$. Fragmentasi ini terbentuk akibat hilangnya 2 gugus - $\mathrm{CH}_{3}$ dari DMMP $\left(\mathrm{C}_{3} \mathrm{H}_{9} \mathrm{O}_{3} \mathrm{P}\right)$. Spektrum pada $\mathrm{m} / \mathrm{z} 94$ yang merupakan base peak diikuti oleh adanya fragmentasi yang kehilangan gugus $-\mathrm{CH}_{3}$ pada $\mathrm{m} / \mathrm{z}=79$ $\left(\mathrm{PO}_{3}\right)^{+}$yang karakteristik untuk grup dialkyl methylphosphonate. Secara keseluruhan fragmen yang lainnya terdiri dari $\mathrm{m} / \mathrm{z} 47,63,79,94,109,124$. $^{(2,3,4.5)}$ Spektrum ekstraksi dikhlorometan ini setelah dibandingkan dengan spektrum pada AMDIS Library memberikah hasil yang sama untuk senyawa Dimethyl Methylphosphonat, seperti Gambar 6. Ethyl phosphonicacid ( EPA) adalah senyawa yang sukar menguap dan jenis senyawa precursor bersifat asam, sangat mudah larut dalam air dan karena adanya gugus $\mathrm{OH}$ pada EPA sehingga bersifat lebih polar. Agar dapat dianalisis dengan GCMS maka dilakukan derivatisasi dengan cara sililasi sebelum diinjeksikan ke GCMS. Hasil derivatisasi dari ekstraksi residu tanah dengan air yang membentuk bis (trimethylsilyl) methylphosphonate.
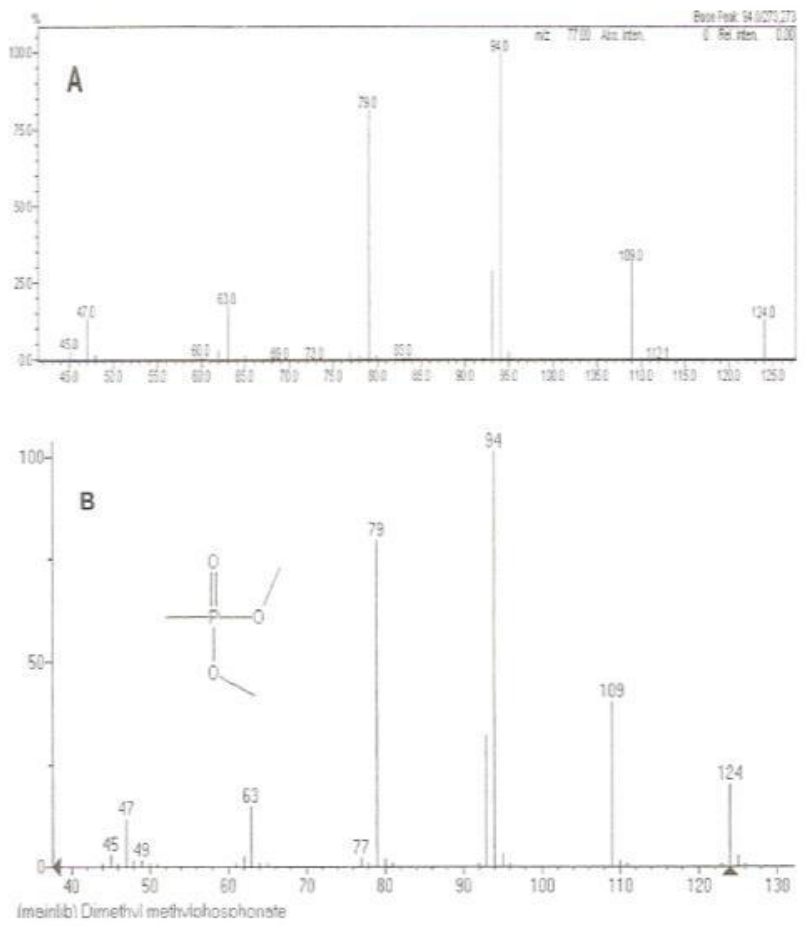

Gambar 4. Spektrum massa Dimethyl Methylphosphonat)

A. Spektrum masa Dimethyl Methylphosphonat dari sampel.

B. Spektrum masa Dimethyl Methylphosphonat (Library)
Seringkali analisis senyawa ini menghasilkan recovery yang lebih rendah karena setelah evaporasi senyawa-senyawa tersebut tertinggal di labu evaporasi namun susah larut dalam pelarut organik. Untuk memperbesar recovery, residu hasil evaporasi terlebih dahulu dilarutkan dengan $1 \%$ triethylamine (TEA) dalam methanol ${ }^{(2,9,12)}$. Larutan dievaporasi kembali hingga kering, residu dilarutkan dengan asetonitril dan di derivatisasi dengan BSTFA.

Total Ion Chromatography (TIC) menunjukkan adanya intensitas puncak pada waktu retensi (Rt) 12,5 menit, dan puncak ini tidak muncul pada larutan blanko yang juga ikut diinjek ke GCMS sebelum injek hasil derivatisasi BSTFA dengan EPA.

Puncak yang dihasilkan pada Rt 12,05 menit belum memberikan intensitas yang lebih besar, karena banyaknya ion-ion pengganggu yang terdapat dalam tanah seperti ion-ion logam $\mathrm{Na}^{+}, \mathrm{Ca}^{+2}, \mathrm{Mg}^{+2}$ dan $\mathrm{K}^{+}$. Untuk menghilangkan ion-ion ini maka setelah diekstraksi dan sebelum diderivatisasi dilewatkan kedalam kation exchange catridge (SCX). Fraksi yang keluar dari SCX dinetralkan terlebih dahulu sebelum dievaporasi sampai kering, larutkan dengan TEA dalam methanol, evaporasi kembali hingga kering dan diderivatisasi dengan BSTFA. Ion-ion pengganggu yang ada dalam tanah menyebabkan proses derivatisasi tidak terjadi pada senyawa karena trimetilsilil tidak akan berikatan dengan alkilphosphonic acid karena cenderung berikatan dengan ion-ion dibandingkan dengan reagen sililasi. . $^{(2,9,12)}$

TIC yang dihasilkan dari reaksi BSTFA dengan EPA yang terdapat dalam tanah tanpa dan dengan menggunakan SCX dapat dilihat pada Gambar 7. Intensitas bis(trimethylsilyl) ethylphosphonate yang dihasilkan jauh lebih tinggi dibandingkan dengan tanpa dilewatkan ke SCX, karena derivatisasi antara BSTFA dengan EPA tidak diganggu oleh ion-ion pengganggu yang ada dalam tanah.

Spektrum massa dari puncak bis(trimethylsilyl) ethylphosphonate pada Rt 12,05 menit ini memberikan ion molekul pada $\mathrm{m} / \mathrm{z} 254$ dan base peak pada $\mathrm{m} / \mathrm{z}=239$ yang berasal dari fragmentasi $\left[\mathrm{M}-\mathrm{CH}_{3}\right]^{+}$ yaitu $\left[\mathrm{C}_{7} \mathrm{H}_{20} \mathrm{O}_{3} \mathrm{PSi}_{2}\right]^{+}$akibat hilangnya gugus $-\mathrm{CH}_{3}$ dari bis(trimethylsilyl) ethylphosphonate $\left(\mathrm{C}_{8} \mathrm{H}_{23} \mathrm{O}_{3} \mathrm{PSi}_{2}\right)$ dan diikuti oleh fragmentasi $\mathrm{m} / \mathrm{z}=73$ yang karakteristik untuk TMS $\left[-\left(\mathrm{CH}_{3}\right)_{3} \mathrm{Si}\right]$ yang khas untuk derivatisasi dengan cara sililasi. Secara keseluruhan fragmentasi terdiri dari $\mathrm{m} / \mathrm{z} 73,211,226,239$ dan $254 . .^{(23,4,5)}$ Spektrum bis(trimethylsilyl) ethylphosphonate 
setelah dibandingkan dengan spektrum pada AMDIS Library memberikah hasil yang sama untuk senyawa bis(trimethylsilyl) ethylphosphonate, seperti Gambar 8 .
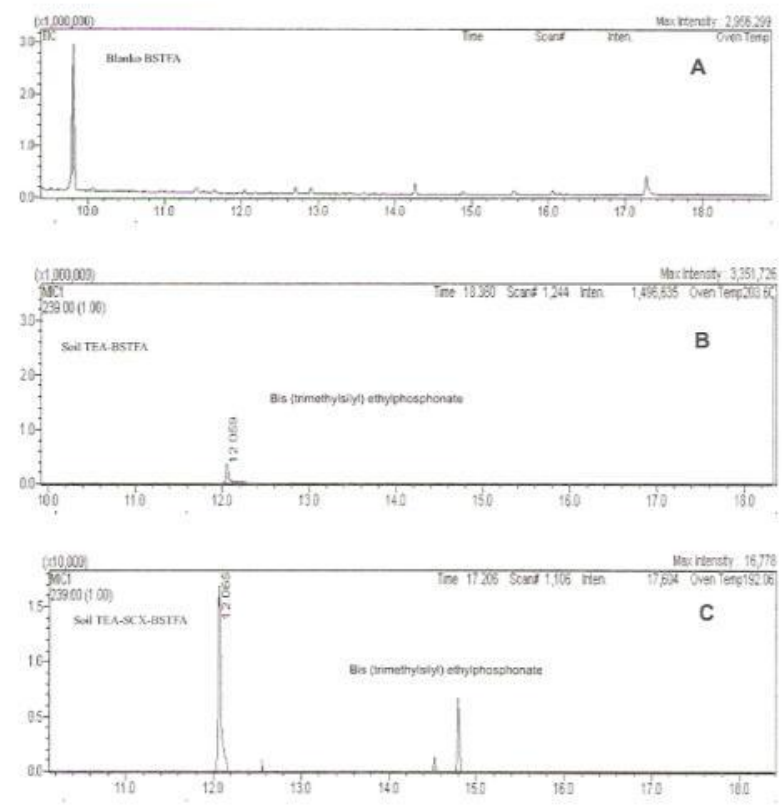

Gambar 7. Total Ion Chromatogram Bis(trimethylsilyl) ethylphosphonate
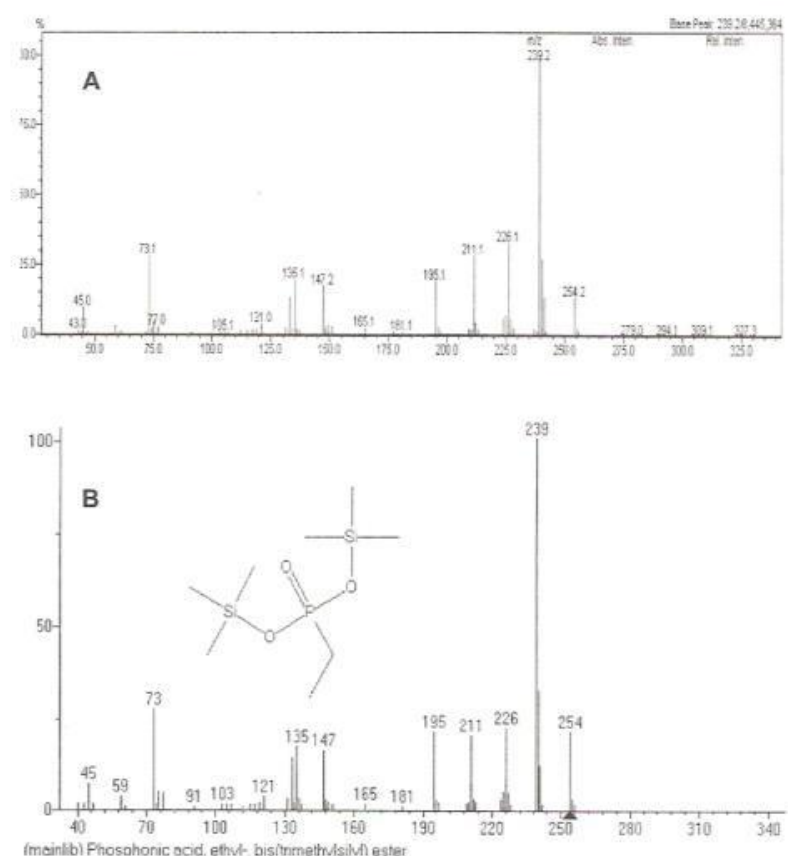

Gambar 4. Spektrum massa massa bis(trimethylsilyl) ethylphosphonate

A. Spektrum masa bis(trimethylsilyl) ethylphosphonate sampel tanah

B. Spektrum masa bis(trimethylsilyl) ethylphosphonate (Library)

\section{Konfirmasi senyawa menggunakan Retention Index} (RI)

Untuk mengkonfirmasi hasil analisis/identifikasi dari senyawa senjata kimia, precursor dan hasil degradasi dari sampel dapat ditentukan dari Retention Index (RI) yang dihitung. RI adalah parameter yang tidak memiliki dimensi, yang mengubah waktu retensi suatu senyawa menjadi nilai baru yang kurang tergantung pada perubahan kecil yang terjadi pada kondisi kromatografi dibandingkan dengan waktu retensi.

Dari analisis DEMP, MPA dalam sampel air dan DMMP, EPA dalam contoh tanah, perhitungan indeks retensi dapat dihitung dengan membandingkan waktu retensi senyawa target terhadap waktu retensi senyawa hidrokarbon yang diinjeksikan secara bersamaan pada instrumen dan kondisi analisis yang sama. Dengan kata lain indeks retensi ialah waktu retensi yang dinormalisir terhadap n-alkana yang dielusi secara berurutan. Pada Tabel 3 RI yang dihasilkan setelah dibandingkan dengan RI Library, perbedaan tidak lebih dari \pm 20 sesuai dengan ketentuan. ${ }^{(10,11)}$

Tabel 3. Perbandingan Nilai Retention Indice

\begin{tabular}{lcc}
\hline \multirow{2}{*}{ Senyawa Precursor } & \multicolumn{2}{c}{ Retention Index (RI) } \\
\cline { 2 - 3 } & Yang di hitung & Library \\
\hline Diethylmethylphosphonate & 1017 & 1013 \\
\hline Bis(trimethylsilyl) methylphosphonate & 1136 & 1148 \\
\hline Dimethylmethylphosphonate & 877 & 893 \\
\hline Bis(trimethylsilyl) ethylphosphonate & 1204 & 1217 \\
\hline
\end{tabular}

\section{KESIMPULAN}

Metode kromatografi gas spektrometry massa elektron ionisasi (GCMS-EI) dapat digunakan untuk analisis dan identifikasi precursor dan hasil degradasi senyawa senjata kimia diethyl methylphosphonat (DEMP), methyl phosphonic acid (MPA) dalam sampel air dan dimethyl methyl phosphonat (DMMP), ethyl phosphonic acid (EPA) dalam sampel tanah. Preparasi dilakukan bertahap dengan mengatur $\mathrm{pH}$ dan senyawa yang bersifat non polar dapat diekstraksi dengan menggunakan pelarut organik dikloromethan dan langsung diinjeksikan ke GCMS. Sedangkan untuk senyawa yang bersifat polar, sukar menguap harus diubah kedalam bentuk derivatnya dengan cara sililasi membentuk senyawa trimetilsilil ester yang mudah menguap. 
Sampel dengan matriks tanah, yang banyak mengandung ion-ion pengganggu dapat dihilangkan dengan dilewatkan kedalam kation exchange cartridge (SCX).

Total Ion Chromatography (TIC) yang dihasilkan dari GCMS dievaluasi dengan menggunakan Library Data Base NIST (National Institute of Standards and Technology), dan AMDIS (Automated Mass Spectral Deconvolution and Identification System). Spektrum yang dihasilkan memberikan nilai base peak pada $\mathrm{m} / \mathrm{z}=97$ untuk diethyl methylphosphonate, $\mathrm{m} / \mathrm{z}=225$ untuk bis(trimethylsilyl) methylphosphonate, $\mathrm{m} / \mathrm{z}=94$ untuk dimethyl methylphosphonate dan $\mathrm{m} / \mathrm{z}=239$ untuk bis(trimethylsilyl) ethylphosphonate sedangkan retention indece (RI) yang dihitung digunakan untuk konfirmasi masing-masing senyawa precursor.

\section{UCAPAN TERIMA KASIH}

Penulis mengucapkan terimakasih kepada almarhum Mieczyslaw Sokolowsky, Dedeh Maklupah dan R. Tina Rosmalina, S.Si atas bantuan diskusi dan teknis dalam pelaksanaan penelitian ini.

\section{DAFTAR PUSTAKA}

1. Convention on the Prohibition of the Development, Production, Stockpiling and Use of Chemical Weapons and on their Destruction, Technical Secretariat of the Organisation for prohibition of Chemical Weapons, the Hague, 1997

2. Sokolowski Mieczyslaw. The OPCW Gas Chromatography/Mass Spectrometer for On-site Analysis. Instrumentation, AMDIS Software and Preparation for Use. Chemical Weapons Convention Chemicals Analysis. Edited by Markku Mesilaako, 2005 John Wiley, pp 52-88

3. Kostiainen Olli. Gas Chromatography in Screening of Chemicals Related to the Chemical Weapons Convention. Chemical Weapons Convention Chemicals Analysis, Edited by Markku Mesilaakso, 2005, pp 187-199
4. Hooijschuur Edwin W.J., Identification of chemicals related to the chemical weapons convention during an interlaboratory proficiency test. Trends in analytical chemistry : vol 21, No 2, 2002 pp. $116-130$

5. Sega Gary A, Tomkins Bruce A, Griest Wayne H. Analysis of methylphosphonic acid, ethyl methylphosphonicacid and isopropyl methylphosphonic acid at low microgram per liter levels in groundwater. Journal of Chromatography A. 79091997$) 143-152$

6. E.R.J.Wils, Gas Chromatography/Mass Spectrometry in Analysis of Chemicals Related to the Chemical Weapons Convention, in R.A. Meyers (Editor), Encyclopedia of Analytical Chemistry, J. Willey and Sons 2005 pp 979 and 249-279

7. Mesilaakso, M., et.al. Verification of Chemicals Related to The Chemical Weapons Convention. Anal Chem. 2000, pp. 899-909

8. Black, R. M., Muir B., Derivatisation Reactions in the Chromatographic Analysis of Chemical Warfare Agents and Their Degradation Products. Journal of Chromatography, 1000: 2003 pp 253281

9. Edwin W.J. Hooijschuur, Charles E. Kientz, Udo A. Th. Brinkman, Analytical Separation Techniques for the Determination of Chemical warfare Agents. Journal of Chromatography A, 982:2002 pp. 177-200

10. Standard Operating Procedure for the Organisation of OPCW Profisiensi Tests, 2011, $\mathrm{QDOC} / \mathrm{LAB} / \mathrm{SOP} / \mathrm{PT} 1$

11. Work Instruction For the Evaluation of the Result of $O P C W$ Proficiency Tests,2011, $\mathrm{QDOC} / \mathrm{W} 1 / \mathrm{LAB}$

12. Kuitunen Marja-Leena. Sample Preparation for Analysis of Chemicals related to the Chemical Weapons Convention.. Encyclopedia of Analytical Chemistry 2005, pp 1055-1071 